Review Article

Open Access

\title{
Yellow fever in Nigeria: a review of the current situation
}

\author{
${ }^{* 1}$ Adogo, L. Y., and ${ }^{2}$ Ogoh, M. O. \\ ${ }^{1}$ Department of Biological Sciences, Faculty of Science and Technology, \\ Bingham University, Karu, Nasarawa State, Nigeria \\ ${ }^{2}$ Institute of Human Virology, Abuja, Nigeria \\ *Correspondence to: adogolillian@gmail.com
}

\begin{abstract}
:
Several African countries including Nigeria have been battling with public health challenges for decades. Nigeria is currently facing several public health emergencies including cholera, circulating vaccine-derived poliovirus infection, cerebrospinal meningitis, monkey pox, measles, Lassa fever, and Yellow fever outbreaks in some states, as well as a humanitarian crisis in the northeast region of the country. Sporadic outbreaks of Yellow fever have been occurring in the country since September 2017 involving all thirty six states of the Federation, resulting in about 90 deaths (case fatality rate of $2.2 \%$ ) and 31 deaths among confirmed cases (case fatality rate of $19.0 \%$ ). Although, there is currently no specific treatment for Yellow fever, vaccination with the Yellow fever vaccine provides life-long protection, and is the most important means of preventing the disease. Despite the availability of an effective vaccine, the re-emergence of Yellow fever is directly correlated with its continuous dissemination in several countries to date. Timely detection of Yellow fever and rapid response through emergency vaccination campaigns are essential for controlling outbreaks. Vector surveillance and control are important components of reducing transmission in epidemic situations. This review attempts to provide update information on the current situation of Yellow fever in Nigeria with highlights on the history, pathogenesis and diagnosis of the disease.
\end{abstract}

Key words: Yellow fever, Nigeria, Outbreaks, Mosquitoes

Received August 24, 2019; Revised September 25, 2019; Accepted September 28, 2019

Copyright 2020 AJCEM Open Access. This article is licensed and distributed under the terms of the Creative Commons Attrition 4.0 International License (http://creativecommmons.org/licenses/by/4.0), which permits unrestricted use, distribution and reproduction in any medium, provided credit is given to the original author(s) and the source.

\section{Fièvre jaune au Nigéria: état des lieux}

\author{
${ }^{* 1}$ Adogo, L. Y., et ${ }^{2}$ Ogoh, M. O. \\ ${ }^{1}$ Département des sciences biologiques, Faculté des sciences et technologies, \\ Université de Bingham, Karu, État de Nasarawa, Nigéria \\ ${ }^{2}$ Institut de virologie humaine, Abuja, Nigeria \\ *Correspondance à: adogolillian@gmail.com
}

\begin{abstract}
Abstrait:
Plusieurs pays africains, dont le Nigéria, luttent contre des problèmes de santé publique depuis des décennies. Le Nigéria est actuellement confronté à plusieurs urgences de santé publique, y compris le choléra, une infection à poliovirus en circulation, une méningite cérébro-spinale, la variole du singe, la rougeole, la fièvre de Lassa et la fièvre jaune dans certains États, ainsi qu'une crise humanitaire dans le nord-est du pays. Des épidémies sporadiques de fièvre jaune se sont produites dans le pays depuis septembre 2017 dans les trentesix États de la Fédération, entraînant environ 90 décès (taux de létalité de 2,2\%) et 31 décès parmi les cas confirmés (taux de létalité de 19,0\%). Bien qu'il n'existe actuellement aucun traitement spécifique contre la fièvre jaune, la vaccination avec le vaccin contre la fièvre jaune offre une protection à vie et constitue le principal moyen de prévention de la maladie. Malgré la disponibilité d'un vaccin efficace, la réémergence de la fièvre jaune est directement corrélée à sa diffusion continue dans plusieurs pays à ce jour. La détection rapide de la fièvre jaune et une réponse rapide au moyen de campagnes de vaccination d'urgence sont essentielles pour contrôler les épidémies. La surveillance et le contrôle des vecteurs sont des éléments importants de la réduction de la transmission en situation épidémique. Cette revue tente de fournir des informations actualisées
\end{abstract}


sur la situation actuelle de la fièvre jaune au Nigéria, en mettant en évidence l'histoire, la pathogenèse et le diagnostic de la maladie

Mots-clés: fièvre jaune, Nigéria, épidémies, moustiques

\section{Introduction:}

Yellow fever is an acute viral haemorrhagic disease that is vaccine preventable, yet it is widely distributed in the tropics of Latin America and Africa where infections cause an estimated 29,000 to 60,000 deaths annually (1). Yellow fever virus is transmitted to humans through the bites of infected mosquitoes (primarily in the genus Aedes), and is principally maintained by a sylvatic (jungle) transmission cycle involving non-human primate reservoirs. Urban Yellow fever outbreaks occur when infected people introduce the virus into heavily populated areas with competent vector populations and insufficient vaccination coverage.

The spectrum of human clinical disease caused by the virus is broad, ranging from asymptomatic infections and mild febrile illness to severe disease and death (2). Although most patients with Yellow fever are asymptomatic, approximately $15-25 \%$ of infected symptomatic persons develop severe disease and the case fatality rate is $20 \%-$ $60 \%$ (3).

A safe and effective vaccine against Yellow fever exists, and some countries require vaccinations for travellers. Other efforts to prevent infection include reducing the population of the transmitting mosquitoes (2). Despite the availability of an effective vaccine, the re-emergence of Yellow fever is directly linked with its continuous dissemination in several countries. Brazil, Angola, Democratic Republic of Congo, and Nigeria accounted for thousands of documented cases between 2016 and 2018 (4), which can be interpreted as a probable indicator of what will occur if no action is taken. Therefore, this review highlights the epidemiological features and the current outbreak of Yellow fever in Nigeria.

\section{Methodology:}

A review of the current situation of Yellow fever in Nigeria was conducted by searching for relevant published materials and bibliographic citations including original and review articles, personal communications, libraries, books, and conference papers through the period 1985 to 2019 with the use of Google scholar engine.

The keywords employed for the search were Yellow fever, history of Yellow fever, Yellow fever in Nigeria, diagnosis of Yellow fever, pathogenesis of Yellow fever, epidemiology of Yellow fever, and current situation of Yellow fever in Nigeria. A total of 205 reference materials were identified but following assessment of the relevance of the materials, only 40 reference materials were selected for the review. The process is depicted in Fig 1.

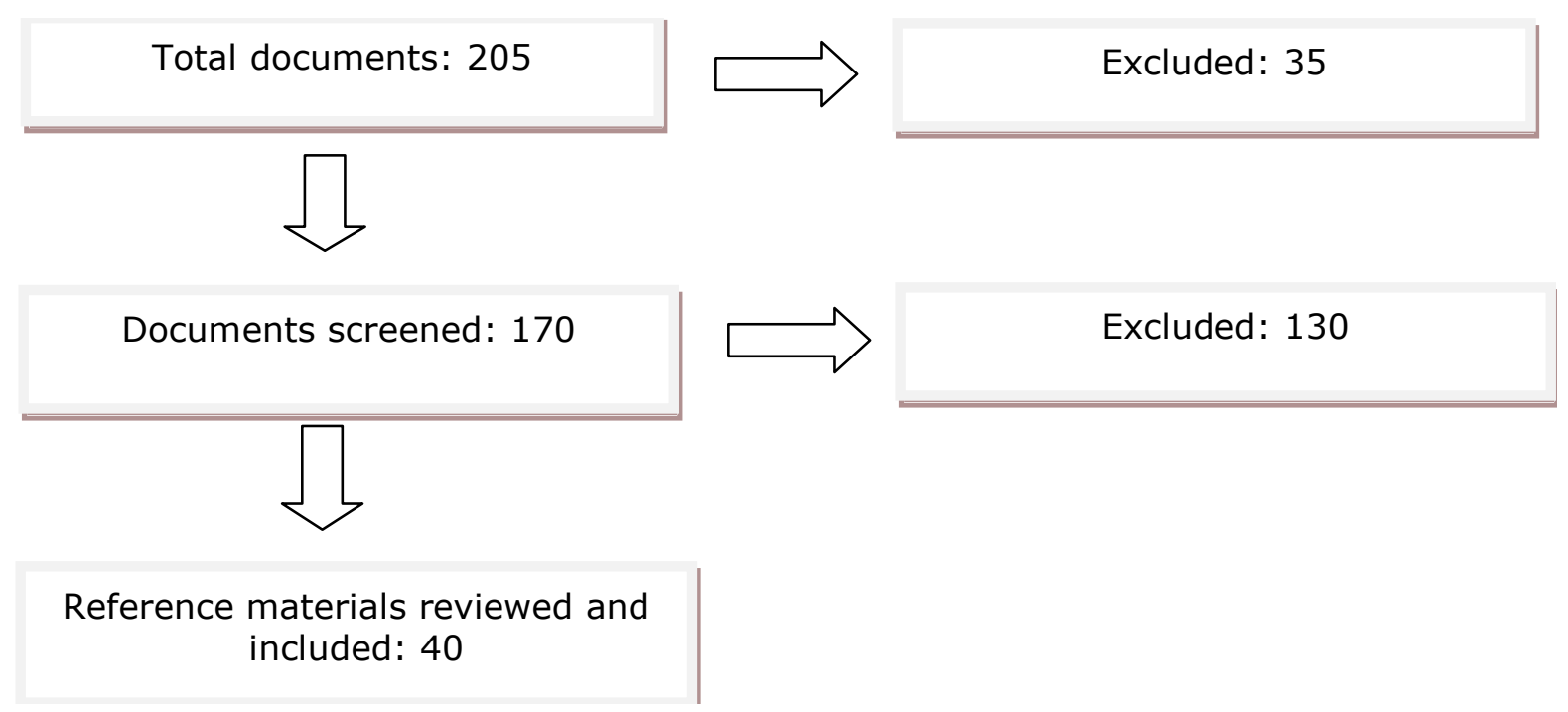

Fig. 1: Flowchart for selection of relevant documents used for the review 


\section{History of Yellow fever}

Yellow fever has had an important role in the history of Africa, America, Europe, and the Caribbean. The evolutionary origins of Yellow fever most likely lie in Africa and scientists believe that Yellow fever evolved in Africa about 3,000 years ago (5). Phylogenetic analyses indicate that the virus originated from East or Central Africa, with transmission between primates and humans, and spread from there to West Africa (6). The virus as well as the vector Aedes aegypti, a mosquito specie, were probably brought to the western hemisphere and the Americas by slave trade ships from Africa after the first European exploration in 1492 (7).

Although it was realized early that the disease was not contagious, the source was wrongly attributed to environmental miasmas. In 1848, Josiah C. Nott suggested that Yellow fever was spread by insects. In 1881, Carlos Finlay proposed that mosquitoes were responsible for disseminating the disease rather than direct human contact $(8$, 9). Due to the extremely high loss of lives to Yellow fever in the Spanish-American War in the 1890s, the United States Government dispatched a team of doctors in the Army led by Walter Reed to Cuba to investigate the cause of Yellow fever. The team successfully proved Finlay's "mosquito hypothesis" for Yellow fever transmission and confirmed that Aedes aegypti mosquito was the primary vector for Yellow fever virus transmission to humans. In ground breaking virologic studies, the team demonstrated that the disease was caused by an agent that could be filtered from the blood of infected individuals (10). Yellow fever virus was the first virus shown to be transmitted by mosquitoes (11). viral morphology is spherical, enveloped, with particle size ranging from 40-50 nm in diameter with icosahedral nucleocapsid symmetry and surface projections of 5 to 10 $\mathrm{nm}$. Its nucleic acid is linear, positive-sense, single-stranded RNA and 11 kilo base long. Mature Yellow fever virions are icosahedral and comprise a nucleocapsid (made of capsid protein subunits) surrounded by a lipid bilayer derived from host membranes. The viral envelope is studded with dimers of envelope (E) glycoprotein and membrane (M) protein (Fig 2). The $E$ glycoprotein is the major component of the virion surface and possesses most of the biologic activity, including cell-surface receptor binding, virion assembly and fusion activity at low $\mathrm{pH}$, and immunogenicity (12). The virions are stable at slightly alkaline $\mathrm{pH}(\mathrm{pH} 8.0)$ and low temperatures, but are readily inactivated at acidic $\mathrm{pH}(\mathrm{pH}<4.0)$, temperatures of $\geq 56^{\circ} \mathrm{C}$ for 30 minutes, organic solvents, detergents, ultraviolet light, gamma radiation and various disinfectants.

Seven genotypes of the virus have been described; five in Africa and two in South America, and these include; (i) West Africa genotype I which has been associated with Yellow fever outbreaks in Nigeria, Cameroon and Gabon; (ii) West Africa genotype II has been associated with outbreaks in Senegal, Guinea, Ivory Coast and Ghana; (iii) East and Central African genotype is found in Sudan, Ethiopia, Democratic Republic of Congo and Central Africa Republic; (iv) East African genotype circulates in Uganda and Kenya; (v) Angola genotype is found in Angola; (vi) South American genotype I was isolated from Brazil, Bolivia, Colombia, Ecuador, Panama and Venezuela, and (vii) South American genotype II was isolated in Peru, Bolivia and Western Brazil (13).

\section{Structure of Yellow fever virus}

The Yellow fever virus belongs to the family Flaviviridae and genus Flavivirus. The

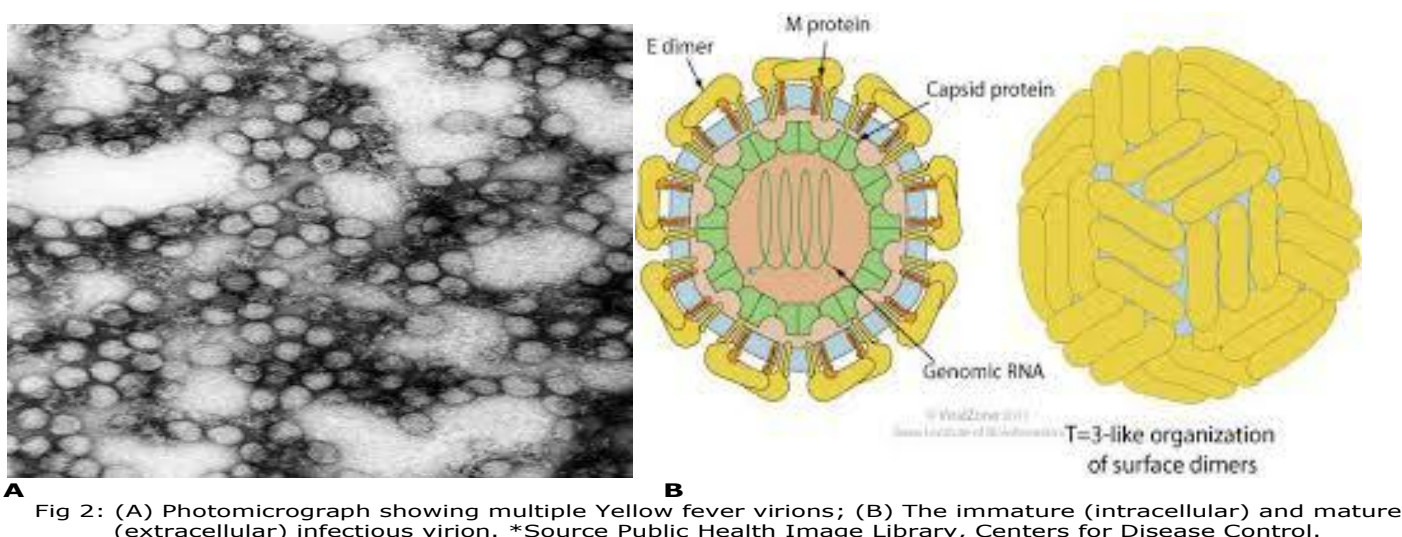




\section{Mode of transmission}

Yellow fever virus is mainly transmitted through the bite of the Yellow fever mosquito Aedes aegypti, but other Aedes mosquitoes such as the tiger mosquito Aedes albopictus can also serve as a vector for this virus. Like other arboviruses which are transmitted by mosquitoes, Yellow fever virus is taken up by a female mosquito when it ingests the blood of an infected human or another primate. The virus reaches the stomach of the mosquito, and if the concentration is high, the virions can infect epithelial cells and replicate within the cell, from where they reach the haemocoel (the blood system of mosquitoes) and then the salivary glands. Transovarial and transtadial transmissions of the virus within $A$. aegypt are indicated. This refers to the transmission from a female mosquito to her eggs and then larvae. This infection of vectors without a previous blood meal seems to play a role in single, sudden breakouts of the disease (14).

When next the infected mosquito sucks blood, it injects its saliva into the wound. An infected female mosquito inoculates approximately 1,000 to 100,000 virus particles intradermally during blood feeding. Virus replication begins at the site of inoculation (in dendritic cells of the epidermis) and spreads through lymphatic channels to regional lymph nodes and then the bloodstream.

Three epidemiologically distinct infectious cycles occur, in which the virus is transmitted from mosquitoes to humans or other primates, and this includes jungle or forest (sylvatic), intermediate (savannah), and urban cycle (Fig 3). The sylvatic cycle involves transmission of the virus between non-human primates (e.g. monkeys) and mosquito species such as Aedes africanus (in Africa) or mosquitoes of the genera Haemagogus and Sabethes (in South America) which serve as vectors found in the forest canopy. The virus is transmitted by mosquitoes from monkeys to humans when humans are visiting or working in the jungle. In Africa, an intermediate (savannah) cycle exists that involves transmission of virus from mosquitoes to humans living or working in jungle border areas. In this cycle, the virus can be transmitted from monkey to human or from human to human via mosquitoes of the genus Aedes. The urban cycle involves transmission of the virus between humans and urban mosquitoes, primarily Aedes aegypti. It is well adapted to urban areas, and can also transmit other viruses, including Zika, Dengue and Chikungunya. The virus is usually brought to the urban setting by a viraemic human who was infected in the jungle or savannah (15).

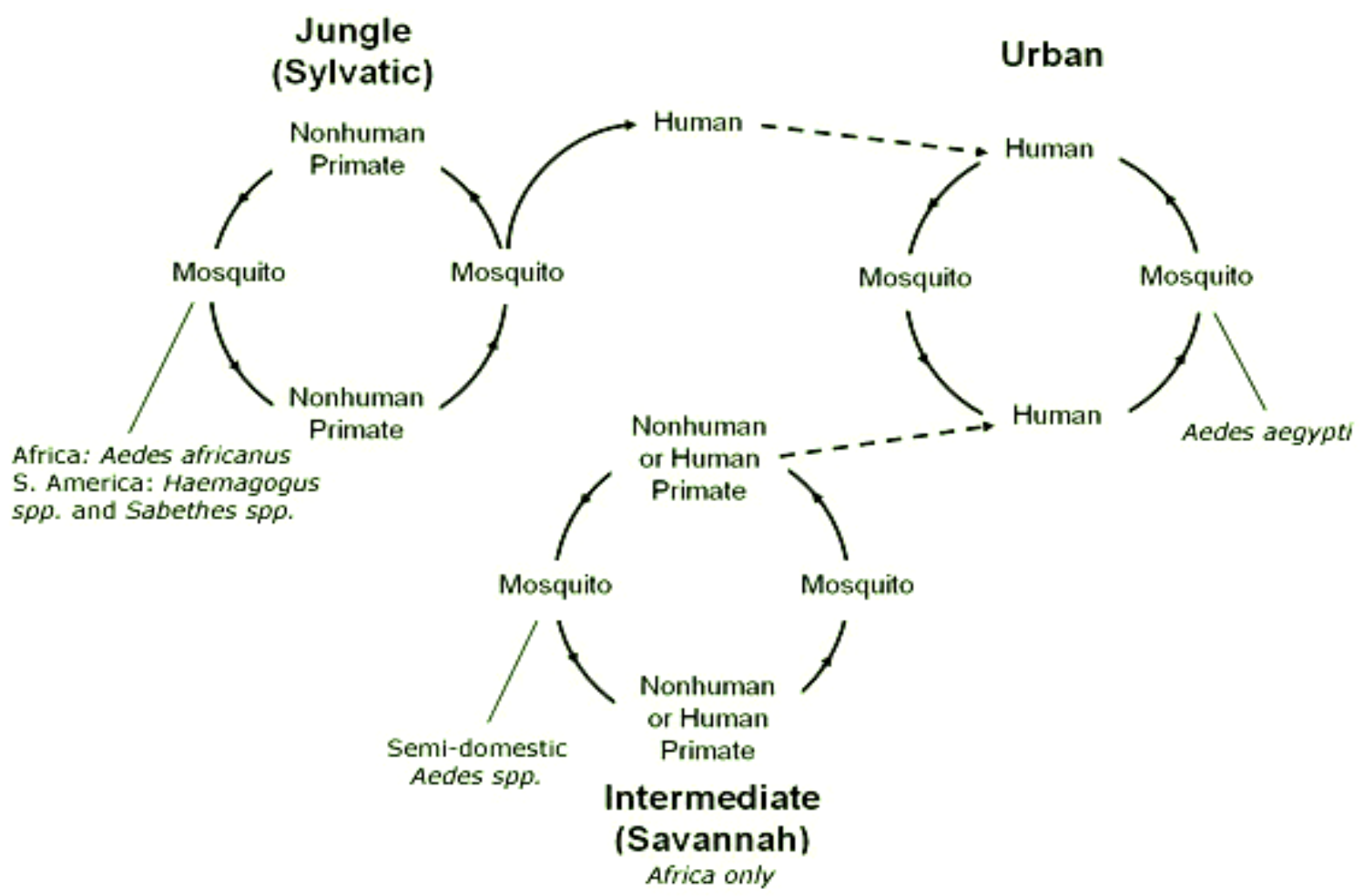

Fig 3: Transmission cycles of Yellow fever virus. *Source: CDC, 2019 


\section{Pathogenesis of Yellow fever:}

\section{Virus replication}

The virus gains entrance through receptor-mediated endocytosis. A capsid protein facilitates viral binding while a membrane protein ( $E$ protein), which is a minor glycoprotein, initiates infection and mediates viral entry. The interaction between Yellow fever virus and cell is extremely complex, as the virus has adapted to exploit the host's machinery for macromolecular synthesis for its own propagation and to antagonize or circumvent antiviral responses. The virus modulates pattern recognition receptors (PRR), stress granules, and membranous structures to promote crucial steps in its life cycle (16).

The Yellow fever virus like other extracellular flavivirus particles bind to target cells by interaction with cell-surface receptors which are yet to be identified, and are internalized by receptor-mediated endocytosis. A conformational rearrangement of the $\mathrm{E}$ glycoprotein occurs in the lower $\mathrm{pH}$ environment of the endosome, which facilitates fusion of the viral lipid envelope with the endosomal membrane and release of the nucleocapsid into the cell's cytoplasm (17). After the nucleocapsid disassembles, replication proceeds with the immediate translation of the genome. The newly translated and processed viral non-structural (NS) proteins associate to form the replicase. The non-structural protein 1 (NS1) may play a role in RNA replication, NS2A protein is involved in RNA replication and packaging, NS2B and NS3 form a complex and are involved in polyprotein processing and replication of RNA $(18,19)$. The replicase recognizes secondary structure in the $3^{\prime}$ terminus of the genomic RNA and the RNAdependent RNA polymerase. NS5 initiates the synthesis of full-length negative-sense RNA copies from the genome template. These negative-sense RNAs are rapidly transcribed to produce progeny positive-sense RNA genomes.

Flavivirus replication occurs in association with host cell membranes (20). RNA synthesis occurs in the cytoplasm and protein synthesis takes place in the endoplasmic reticulum (ER). Infection causes dramatic proliferation of spherical invaginations known as vesicle packets (VP) in the perinuclear region of the $E R$, at least in part through activity of the NS4A protein $(21,22$, 23). The localization of several viral NS proteins and dsRNA replicative intermediates in VPs suggests they are the site of viral replication (24).

Depending on the virus strain and cell type, the synthesis of Yellow fever virus
RNA is detectable within three to six hours after infection, and progeny virions are released by about 12 hours. Immature, non infectious virions assemble within the ER, where viral RNA complexes with the $C$ protein and is packaged into an ER-derived lipid bilayer containing heterodimers of the prM and $E$ proteins, indicating that budding through the host cell membrane occurs intracellularly (25). Subcellular transport of immature flavivirus particles to the cell surface is thought to occur by the translocation of immature virion-containing vesicles from membranous components of the cell to the plasma membrane. Fusion of these vesicles with the plasma membrane then releases the vesicle contents including virions into the extracellular environment.

During assembly and transport of immature virions, the precursor to structural proteins ( $C$, prM, and $E$ ) protects these proteins from undergoing irreversible conformational changes in acidic compartments of the secretory pathway. Virion maturation occurs in the transgolgi network by a delayed furin-mediated cleavage of the prM to $M$, triggering rearrangements in the $E$ protein that promote infectivity (26). Infectious, mature virus particles are released by exocytosis into the extracellular medium. The mean time between being bitten by the infected mosquito and the onset of the first symptoms is 3-6 days but may reach $10-15$ days $(27,28)$.

\section{Pathological changes in organs}

After invasion in the host, Kupfer cells (fixed liver macrophages) are infected within 24hours. The infection quickly disseminates to the kidneys, lymph nodes, spleen, and bone marrow. Renal failure occurs as renal tubules undergo fatty change and eosinophilic degeneration, likely due to direct viral effect, hypotension, and hepatic involvement. The liver is the most important organ affected in Yellow fever. Hepatocellular damage is characterized by lobular steatosis, necrosis, and apoptosis with subsequent formation of 'Councilman bodies', which are degenerative eosinophilic hepatocytes. The kidneys also undergo significant pathologic changes. Central nervous system (CNS) findings can be attributed to cerebral edema and hemorrhages compounded on metabolic disturbances.

The bleeding diathesis of this disease is secondary to reduced hepatic synthesis of clotting factors, thrombocytopenia and platelet dysfunction. The terminal event of shock can be attributed to a combination of direct parenchymal damage and a systemic inflammatory response. Encephalopathy is also a common feature of Yellow fever (29, 
30). Finally, circulatory shock develops secondary to cytokine storm, with evidence of increased levels of interleukin (IL)-6, IL-1 receptor antagonist, interferon-inducible protein-10, and tumor necrosis factor-alpha.

\section{Clinical features of Yellow fever}

The clinical manifestations of Yellow fever vary from an asymptomatic, abortive infection in which symptoms abate rapidly after the first phase to an invariably fatal, fulminating disease with symptoms following a biphasic course. Yellow fever shares clinical features with other viral haemorrhagic fevers (VHFs) such as Dengue haemorrhagic fever, Lassa fever, and Crimean-Congo haemorrhagic fever. The clinical manifestation of Yellow fever is biphasic with viraemic (mild to moderate) and toxaemic (severe/malignant) phases.

The viraemic phase is characterized by mild infection with fever, headache, chills, back pain, fatigue, loss of appetite, muscle pain, nausea, and vomiting. Mostly, these symptoms subside within 2 to 4 days, characterizing mild and moderate cases, which are estimated to account for $20-30 \%$ of infected patients.

The toxemic phase takes place in approximately $15 \%$ of patients and begins after a period of clinical improvement that follows the first phase, lasting 24 hours on average (25). It is characterized by recurdescence of high fever, chills, worsening of headache and myalgia, and involvement of various organs and systems. Hepatic induced coagulopathy produces severe haemorrhagic manifestations with petechiae, ecchymoses, epistaxis, and the characteristic "black vomit" (haematemesis), and gastrointestinal haemorrhage. Yellow fever is distinguished from other viral haemorrhagic fevers by the characteristic severity of liver damage and appearance of jaundice. Moreover, damage to the kidneys frequently leads to extreme albuminuria and acute renal failure.

Antibodies can be detected at this stage while viremia is usually absent. Cardiovascular dysfunction and neurological impairment with seizures usually occurs (3). Often, the unusual pairing of fever with bradycardia (Faget sign) is observed. Late CNS manifestations such as confusion, seizure and coma are also observed. Up to half of these patients progress to death in 10 to 14 days, and the rest recover without significant sequelae $(31,26)$.

\section{Diagnosis of Yellow fever}

Presumptive diagnosis is based on the patient's clinical features, vaccination status, and travel history, including destination, time of year, and activities. Clinical diagnosis requires that Complete blood count, urinalysis, liver function tests, coagulation tests, viral blood culture, and serologic tests should be obtained. Yellow fever is easily confused with Dengue, Lassa, Ebola, malaria, typhoid, hepatitis, and other diseases, as well as poisoning, hence these diseases should be excluded, and laboratory confirmation of Yellow fever should be done.

Laboratory diagnosis of Yellow fever is generally accomplished by molecular biology studies such as reverse transcriptionpolymerase chain reaction (RT-PCR), immuno histochemistry/histopathological analysis and serological tests $(32,33)$.

\section{Treatment of Yellow fever}

There is no specific antiviral drug available for the treatment of Yellow fever and there has not been any successful treatment of the disease with interferongamma, ribavirin and EICAR drugs (34). Studies $(35,36)$ revealed that Yellow fever virus is susceptible to sofosbuvir both invitro and invivo suggesting that this drug may represent a novel therapeutic option for the treatment of Yellow fever.

However, severely ill patients are usually admitted to the intensive care unit and provided with vasoactive medications, fluid resuscitation, and ventilator support. In patients with moderate or severe clinical status, hospitalization with clinical and laboratory follow-up are crucial. In mild cases, outpatient care with daily visits is considered, with guidance on the risk of rapid aggravation. In this case it is necessary the prescription of hydration ( $60 \mathrm{~mL} / \mathrm{kg} /$ day) and drugs dependent on hepatic metabolism should be avoided. Fresh frozen plasma and vitamin $\mathrm{K}$ have been administered to replenish clotting factors.

\section{Prevention \& control of Yellow fever}

A safe, reasonably priced and extremely effective vaccine is available for the prevention of Yellow fever. Sustained immunity and life-long protection against Yellow fever disease is conferred adequately with a single dose of Yellow fever vaccine. The elimination of prospective mosquito breeding sites, application of larvicides to water storage containers and other places where standing water collects can reduce the threat of Yellow fever transmission in urban areas.

Both vector surveillance and control are components of the prevention and control of vector-borne diseases. Personal 
protective measures such as clothing minimizing skin exposure and repellents are recommended to avoid mosquito bites. Health information related to the diseases should be made available to the entire populace.

\section{Epidemiology of Yellow fever}

\section{Global}

Vaccination has decreased worldwide epidemics of Yellow fever, but the infection has re-emerged in many parts of Africa and South America. No one is immune from Yellow fever, and it occurs in people of all ages and races. The highest mortality rates are reported in infants and elderly, who often have depressed immune systems. Most cases are diagnosed in unvaccinated travellers to sub-Saharan Africa or South America. Occasionally, travellers from endemic countries may carry the disease to uninfected regions. To avoid the importation of the disease, many countries require proof of Yellow fever vaccination prior to issuing a visa, especially if travellers are going to, or have visited, Yellow fever endemic areas (37).

Yellow fever is endemic in tropical and subtropical areas in Africa and South America (38). According to the World Health Organization, 47 countries in Africa and 13 countries in South America are endemic for Yellow fever $(39,40)$. The World Health Organization estimates from the early 1990s indicated that 200,000 cases of Yellow fever, with 30,000 deaths, were expected globally each year, with 90\% occurring in Africa (41). Fig 4 shows areas with risk of Yellow fever virus transmission in Africa and hence the great need for vaccination. The recent situation of Yellow fever in some continents with major outbreaks is described below.

\section{The Americas}

Between January 2017 and December 2018, six countries and territories in the region of the Americas reported confirmed cases of Yellow fever; Bolivia, Brazil, Colombia, Ecuador, French Guiana, and Peru. The number of cases reported during this period in the region of the Americas exceeded the number reported in several decades. Yellow fever outbreak in the State of Minas Gerais, Brazil was reported in 2002-2003, when 63 confirmed cases, including 23 deaths (case fatality rate, 37\%) were detected (42).

In December 2016, cases of Yellow fever were reported in Minas Gerais again and the outbreak extended to areas located in proximity of the State. As of mid-April 2017, a total of 2,422 cases (including 623 confirmed, 1128 discarded and 671 suspected cases under investigation) were reported (43). These included 326 deaths (209 confirmed, 53 discarded and 64 cases under investigation). The case fatality rate among confirmed cases was 34\% (43). In 2019, Brazil and Peru reported confirmed cases that occurred between December 2018 and January 2019.

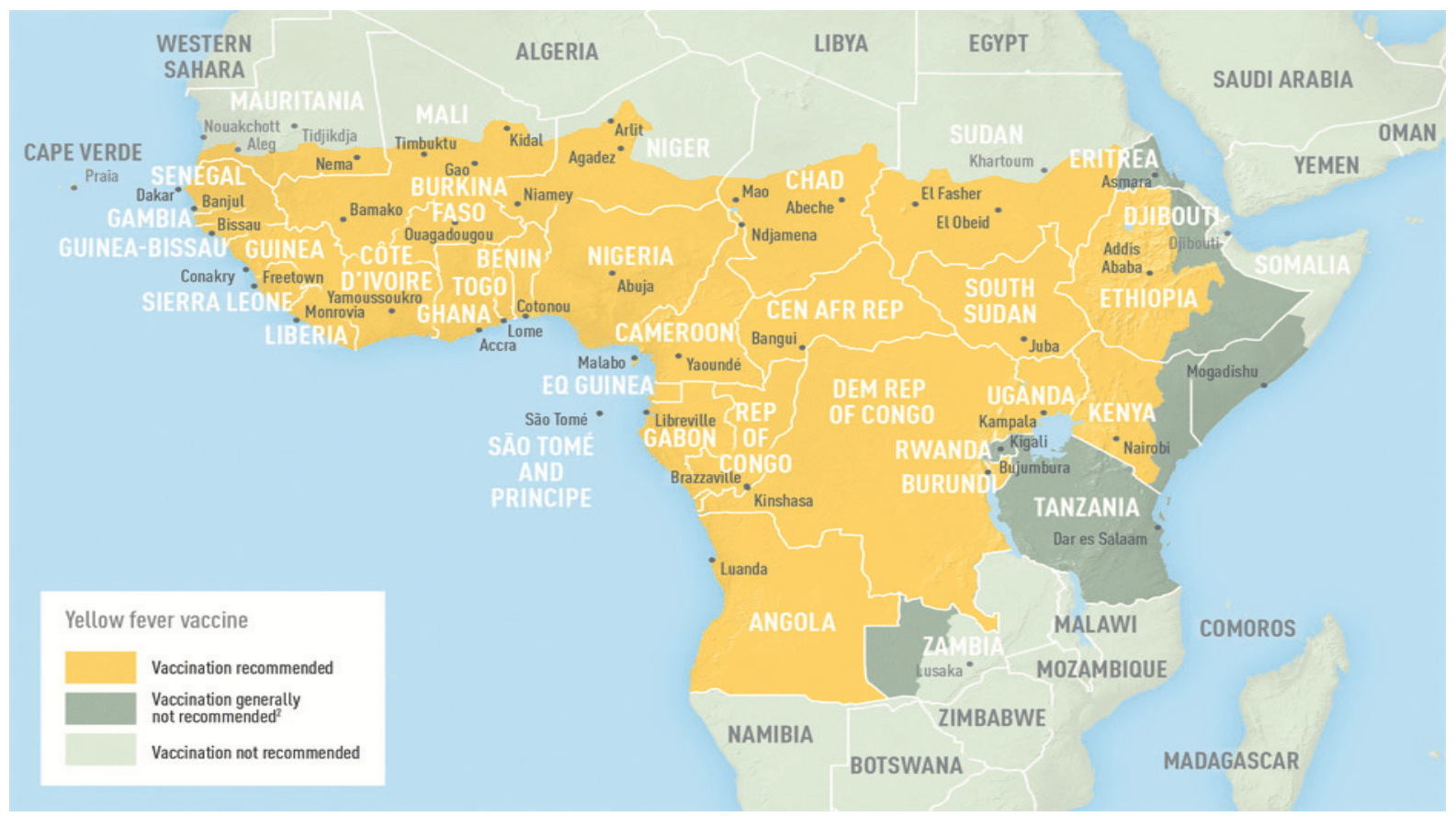

Fig 4: Areas with Risk of Yellow Fever Virus Transmission in Africa *Source: CDC, 2019 
In Brazil, it is currently the period which has historically been recognized as having the highest transmission (seasonal period), which occurs between December and May. The expansion of the historical area of Yellow fever transmission to areas previously considered risk-free led to two waves of transmission, one during the 2016/2017 season, with 778 human cases including 262 deaths, and another during the 2017/2018 season, with 1,376 human cases, including 483 deaths (43). In the current season (2018/2019), 12 confirmed human cases, including 6 deaths, have been reported in the municipalities of Eldorado (9 cases), Jacupiranga (1 case), Iporanga (1 case), and Cananeia (1 case), all of which are located in the southern part of São Paulo State (33). Among these confirmed cases, 83\% (10/12) are male, the median age is 45 years, and $83 \%(10 / 12)$ are rural workers.

Additionally, the Paraná Secretariat of Health reported that tests performed on dead monkeys in Antonina, on the Paraná coast, were positive for Yellow fever. Human cases reported during the current 2018/2019 season in four municipalities of São Paulo State, as well as the confirmation of epizootics in the State of Paraná, mark the beginning of what could be a third cycle and a progression of the outbreak towards the Southeast and South regions of the country (43).

\section{Africa}

An estimated $90 \%$ of Yellow fever cases occur on the African continent (44). In 2008 , the largest number of recorded cases was in Togo. In late 2015 to December 2016, the largest outbreak of Yellow fever originated from Angola and spread to neighbouring countries (45). The outbreaks started in a crowded urban environment from Luanda and spread quickly to the rest of the country and beyond borders. Cases of Yellow fever in Angola had been exported to countries including Democratic Republic of Congo (DRC), Kenya and Mainland China (46). From early December 2015 to late July 2016, a total of 3818 cases were reported. Among these, 3294 cases had laboratory tests and 879 were confirmed. The majority of the confirmed cases were in males aged 15-19 years, followed by 20-24 years (47).

As of mid-June 2016, almost half of the country's population of $10,641,209$ people have been vaccinated. This response exhausted the global stockpile of Yellow fever vaccines several times (41). The last case in Angola was detected on 23 June 2016. In late December 2016, Angola declared the end of the Yellow fever outbreak (40). Overall, Angola reported a total of 4,306 cases and 376 deaths, of which 884 cases and 121 deaths were laboratory confirmed (47).

The DRC is located in a geographical area known to be Yellow fever endemic, and autochthonous cases are regularly reported. On 22 March 2016, the National International Health Regulations (IHR) Focal Point of the DRC notified WHO of cases of Yellow fever in connection with the outbreak occurring in Angola. The last case in DRC was detected on 12 July 2016. In mid-February 2017, DRC declared the end of the Yellow fever outbreak (47). A total of 2987 cases of were reported from all 26 provinces of DRC during the outbreak, of which 81 cases were laboratory confirmed, with 16 deaths (case fatality rate among confirmed cases $20 \%$ ). Most of the confirmed cases acquired the infection from Angola (48).

\section{Yellow fever in Nigeria}

\section{Historical perspectives}

The earliest outbreak of Yellow fever in Nigeria was reported in Lagos in 1864, with subsequent regular outbreaks. Two epidemics occurred in Ogbomosho in 1946 and in Eastern Nigeria in 1951-1953 (49). The 1969 Yellow fever outbreak in Jos, Plateau State was the first recognized occurrence of epidemic Yellow fever in Nigeria in 17 years at that period. The first laboratory confirmation of Yellow fever was in a patient whose illness began on $7^{\text {th }}$ September 1969.

The Virus Research Laboratory of the University of Ibadan, Nigeria, was informed that suspected cases of Yellow fever had occurred in Jos on 23 October 1969. The diagnosis was confirmed by virus isolation and the existence of a widespread outbreak on the Jos Plateau and adjacent areas was established. This was the first recognized epidemic of Yellow fever in Nigeria since 1953 (50). Approximately 252 patients with Yellow fever were hospitalized between September and December, 1969. The case fatality rate for hospitalized patients was approximately $40 \%$. It was estimated that up to 100,000 cases of Yellow fever may have occurred during the epidemic (50).

\section{Current situation in Nigeria}

For a space of 21 years, no further confirmed cases of Yellow fever was reported until September 2017 when Yellow fever was established in a seven-year old child in Ifelodun Local Government Area of Kwara State. Since then, Nigeria has been experiencing periodic outbreaks of the disease. On 22 November 2018, a cluster of suspected Yellow fever cases and deaths in 


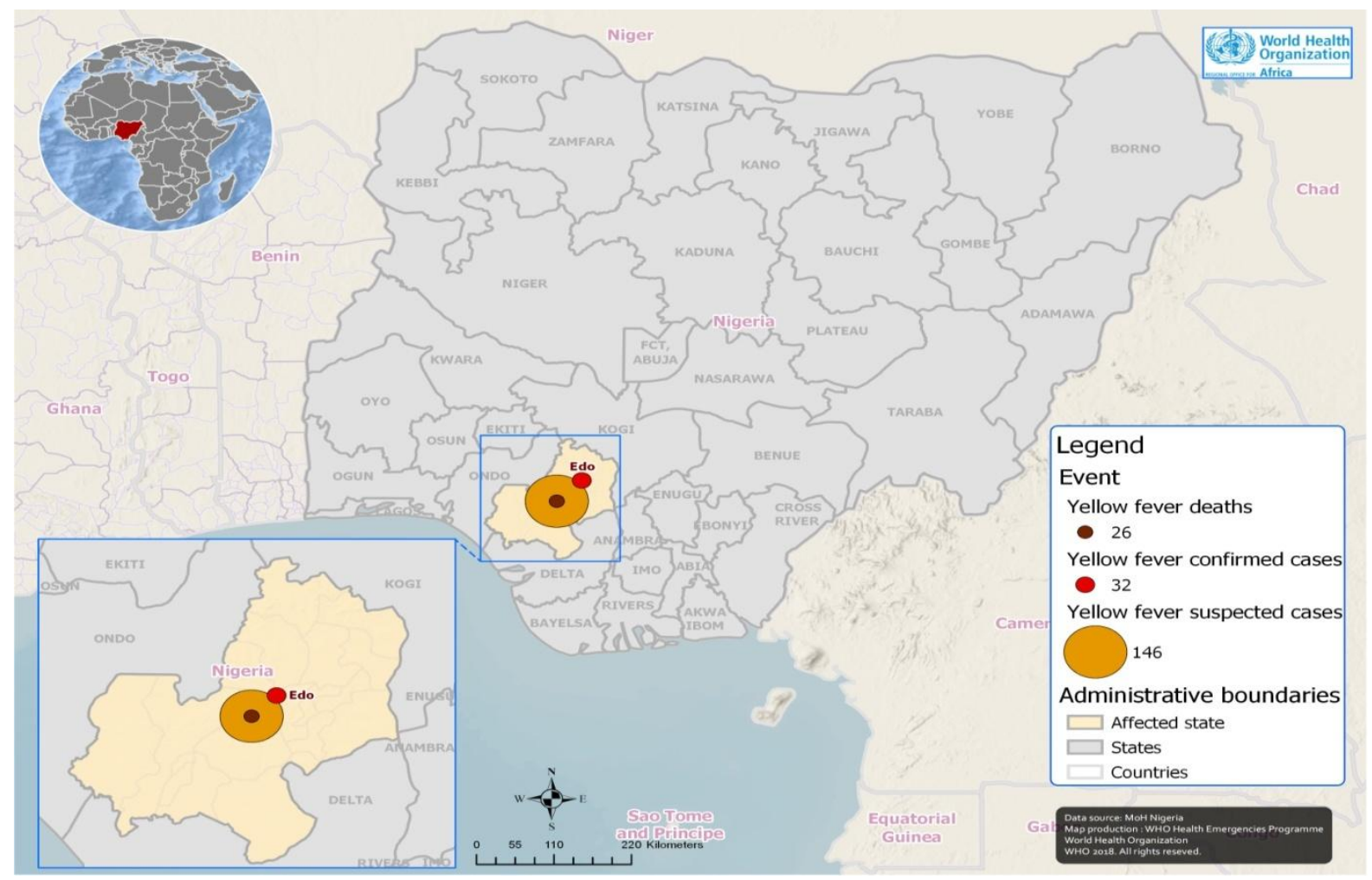

Fig 5: Confirmed and suspected Yellow fever cases in Edo State outbreak, Nigeria, data as of 31 December 2018 *Source; WHO, 2019

Edo State, Nigeria was reported to the World Health Organization. Edo State is also a known endemic area for Lassa fever which was initially suspected as causing the outbreak. From 22 September through 31 December 2018, a total of 146 suspected, 42 presumptive positive, and 32 confirmed cases, including 26 deaths, have been reported across 15 of 18 Local Government Areas of the State (51) (Fig 5). The most affected age group was $10-19$ years with 48 cases $(33 \%)$, followed by the age group 2029 with 36 cases (25\%). Primarily, the affected LGAs were in the rural areas however, suspected cases were reported from three urban LGAs at the end of November 2018. There was also a report of two presumptive positive and one confirmed case in Oredo LGA, which included the densely populated State capital, Benin City, of about 1.5 million inhabitants.

From 2017 to 2018, 163 cases were confirmed in 17 States; Kwara (8), Kogi (12), Kano (1), Zamfara (19), Kebbi (7), Nasarawa (3), Niger (1), Katsina (2), Edo (90), Ekiti (2), Rivers (1), Anambra (1), FCT (11), Benue (1), Delta (1), Ondo (2) and Abia (1). From September 2017 to December 2018, 283 samples (presumptive positive, 246 and inconclusive, 37) were sent to Institute
Pasteur (IP) Dakar for reconfirmation. All the States in Nigeria (including the Federal Capital Territory) reported 4,132 suspected cases in 616 LGAs. Of all suspected, probable and confirmed cases, 90 deaths were recorded with 31 deaths among confirmed cases. The case fatality rate for all cases (suspected, probable and confirmed) was $2.2 \%$ and $19.0 \%$ for confirmed cases. Fig 6 shows the map of Nigeria revealing States with suspected, probable and confirmed cases of Yellow fever as at December 2018 (51).

In May 2019, 332 suspected cases of Yellow fever were reported, with 1 presumptive positive and 1 inconclusive case. The Nigerian Center for Disease and Control (NCDC) Central Public Health Laboratory (CPHL) reported 1 presumptive positive case from Akoko South East LGA in Ondo State, and 1 inconclusive case from Gokona in Rivers State. Three new confirmed cases from IP Dakar were received from Onitsha North LGA in Anambra State, 1 from Arewa Danladi LGA in Kebbi State and 1 from Kware LGA in Sokoto State. These were the last IP Dakar confirmed cases received on 24 May 2019. Sokoto is the latest State to report a confirmed case since the onset of the outbreak in 2017 (51). 


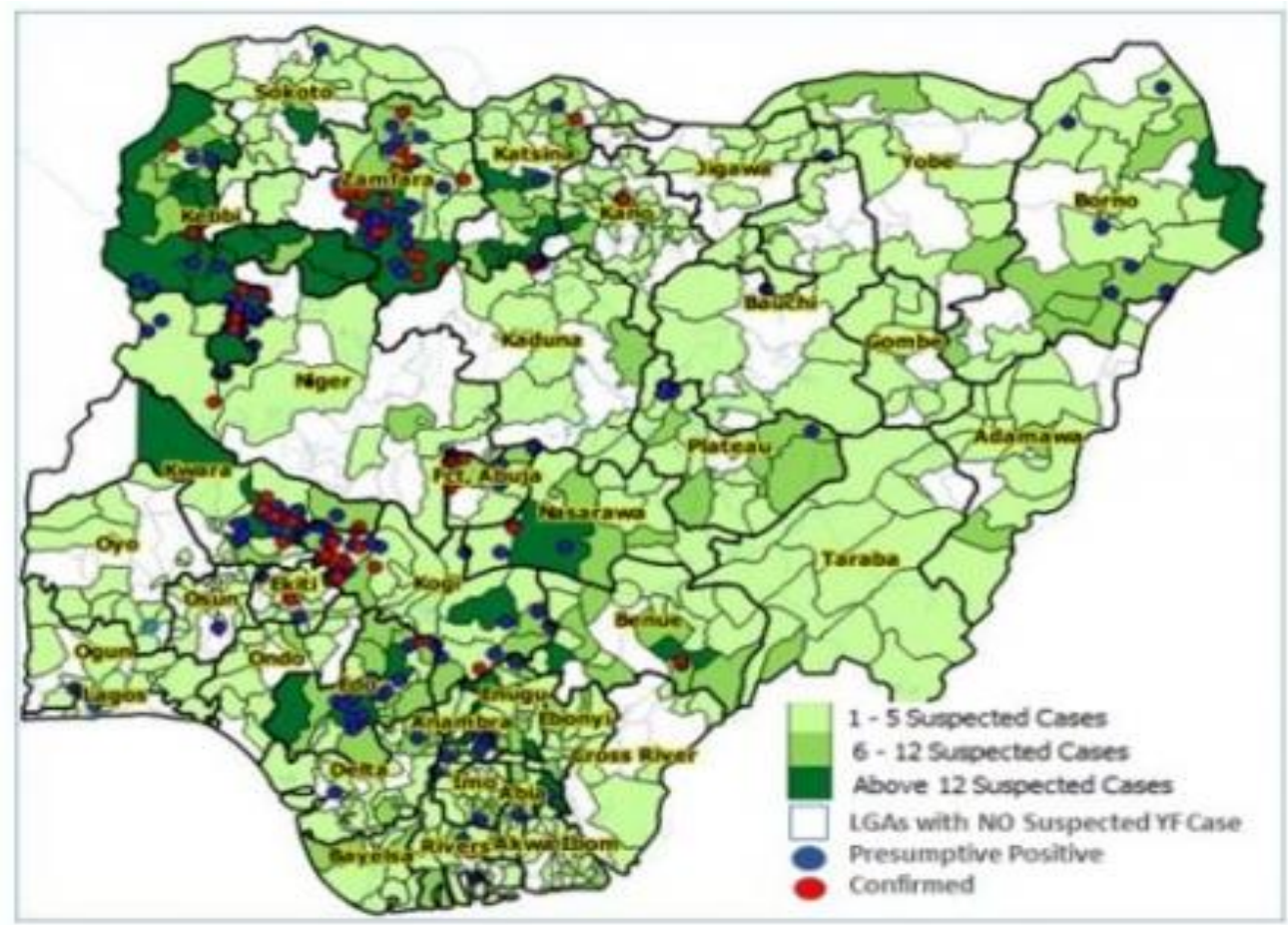

Fig 6: Map of Nigeria showing States with suspected, probable and confirmed cases of yellow fever as at $30^{\text {th }}$ December, 2018. Source* NCDC, 2019

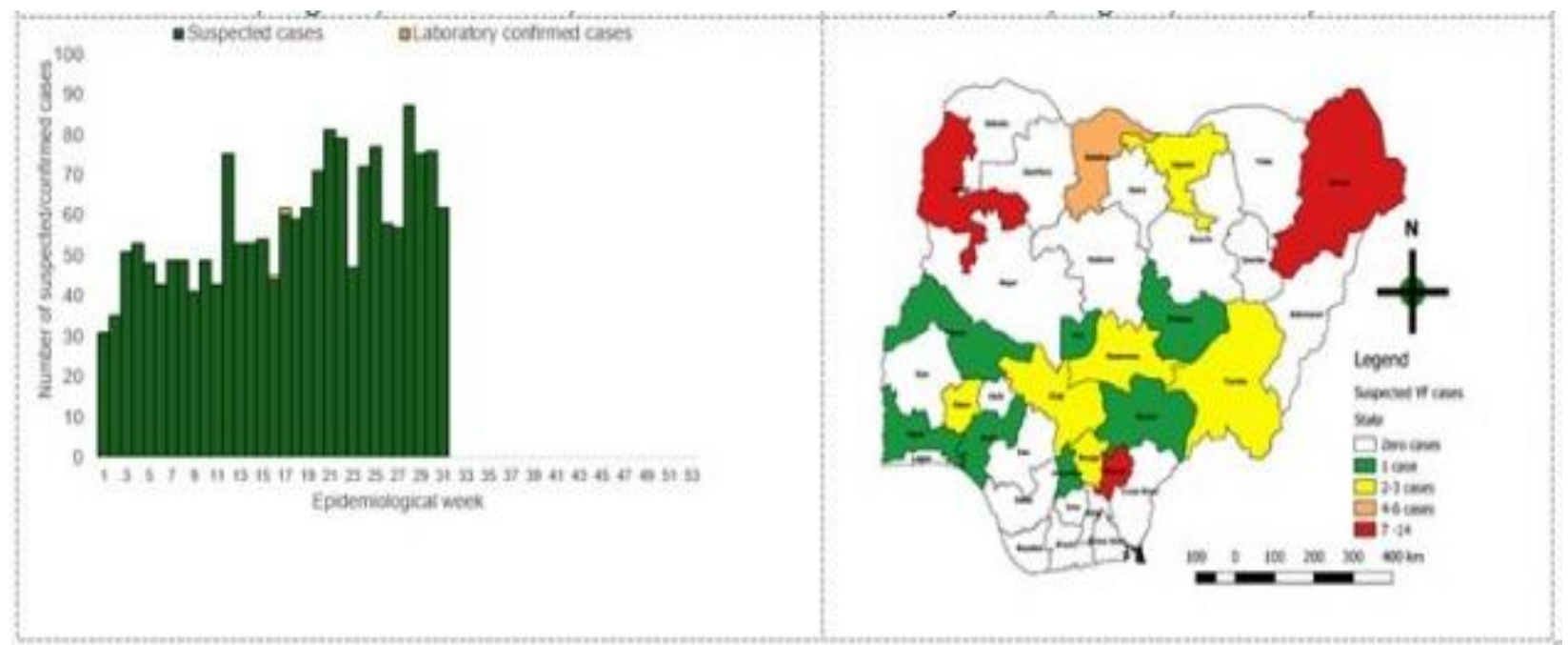

Fig 7: Number of suspected and confirmed cases of Yellow fever, week 1-31, 2019 (left) and Map of Nigeria showing the location of suspected cases by State, week 31, 2019 (right). Source* NCDC, 2019

Between 1 January and 31 May 2019, 1,255 suspected cases were reported in 424 LGAs (Fig 7). Laboratories in Nigeria have recorded 37 presumptive positive and 12 inconclusive cases from 12 States in 38 LGAs. From the 37 presumptive and 12 inconclusive samples sent to Dakar, 15 were confirmed and distributed as follows; Edo ( 7 and 1 inconclusive), Ondo (2), Imo (1), Osun (1), Anambra (1), Kebbe (1) and Sokoto (1). One death from suspected Yellow fever case has been recorded from Adamawa State with a case fatality Rate of $0.08 \%$ (51).

In Izzi Local Government Area of Ebonyi State, new cases of infected persons and deaths from fever of unknown origin prompted the State Public Health team to commence investigations. As at 31 July 2019, 3 cases had tested positive for Yellow fever at NCDC's National Reference Laboratory, which triggered an immediate response. The Ebonyi State Epidemiology 
Team is currently guiding the response team and is in collaboration with the NCDC, National Primary Health Care Development Agency (NPHCDA) and the World Health Organisation. Between May 1 and August 7, 2019, Yellow fever cases and 20 deaths were discovered in the study area which was an indication that disease transmission was ongoing and concealed to health authorities in Izzi Local Government Area. However, on 10 August 2019, the NCDC stated in a press release that the agency is aware of a suspected outbreak of Yellow fever in Ebonyi State and has had a Rapid Response Team in partnership with World Health Organization, supporting Ebonyi State's response since 30 July 2019 (52).

\section{Nigeria Public Health response}

A comprehensive and long term strategy to eliminate Yellow fever epidemics globally is built on lessons learned, with the intention of "Eliminating Yellow fever Epidemics" (EYE) by 2026, and its three strategic objectives include; (i) protection of populations at risk; (ii) prevention of international spread, and (iii) rapid containment of outbreaks.

The EYE Strategy places Nigeria as a priority country and over 60 million people are expected to be protected against Yellow fever in the country by the end of 2021. During the $67^{\text {th }}$ Session of the World Health Organization Regional Committee meeting, Health Ministers of African countries including Nigeria agreed on 10 priority actions to guide countries on the eradication of the Yellow fever epidemics by 2026.

The Government of Nigeria launched the Yellow fever reactive immunization campaign with support from the World Health Organization and other collaborators, funded by GAVI, the Vaccine Alliance, in December 2018. The campaign was implemented in 13 LGAs of Edo State, where cases have been confirmed. Due to the incomparable Yellow fever outbreak recently identified in the State, the immunization drive force was enacted. National preventive and reactive mass vaccination ( $\sim 33$ million doses) campaigns have been conducted in the country since 2017. A proposal has been submitted to GAVI, the Vaccine Alliance, to vaccinate ( $\sim 23$ million doses) people in 12 States over the next 3 years (51).

The International Coordination Group (ICG) on Vaccine Provision, funded by GAVI, the Vaccine Alliance, approved release of 3.1 million doses of Yellow fever vaccines. In the same vein, the World Health Organization pledged to donate 12 million doses of Yellow fever vaccines in 2018, and 19 million in 2019 to support Nigeria's campaign against the disease. A rapid response team under the leadership of National Primary Health Care Development Agency (NPHCDA) and Nigeria Centre for Disease Control, composed of National and State Health authorities, and other WHO collaborators, was set up to examine the cases, fortify efforts to reduce virus circulation, and sensitize health workers and communities on methods of preventing Yellow fever.

To ensure that Yellow fever is eradicated from Nigeria, the following measures are recommended; (i) vaccine coverage of over $80 \%$ with a $60-80 \%$ security threshold, are necessary to interrupt local transmission (human-mosquito-human) of Yellow fever virus within a community and to ensure that sporadic unvaccinated cases do not generate additional cases hence, any person 9 months and older should be vaccinated against Yellow fever. Travellers going to Yellow fever endemic countries should receive vaccination against the virus at least 10 days before travel and should take steps to prevent mosquito bites while in the country; (ii) there should be a strong disease surveillance system and diagnostic capacities that will allow for early detection of outbreaks and rapid implementation of control measures that can help mitigate the risk of spread and the use of extensive resources; and (iii) vector surveillance that identifies prevalence of Aedes aegypti and other Aedes stegomyia species should be greatly enhances as this will provide information on the risk of an urban outbreak in the country.

\section{Conclusion:}

Yellow fever is often represented as a neglected disease, yet it still remains a considerable threat to human health and economy, as exhibited by the outbreaks of 2016-2018 in areas with historically low or no Yellow fever activity. Nigeria is one of 50 global partners battling to eliminate Yellow fever within the next 10 years. However, the current report of positive cases and mortality recorded in the year 2019 reveals ongoing transmission in the country. Hence, a holistic approach by relevant stakeholders and the entire populace is required to eliminate Yellow fever in Nigeria.

\section{References:}

1. Garske, T., Van Kerkhove, M. D., Yactayo, S., et al. Yellow fever in Africa: estimating the burden of disease and impact of mass vaccination from outbreak and serological data. PLoS Med. 2014; 6; 11 (5): e1001638.

2. World Health Organization. "Yellow fever Fact sheet N¹00". $2013 a$. 
3. Center for Disease Control. Yellow fever. Atlanta, GA: US Department of Health and Human Services, Center for Disease Control 2018. https://www.cdc.gov/yellowfever/symptoms/ind ex.html

4. Pan American Health Organization. Yellow Fever - Epidemiological Update. Domingo, C., Charrel, R. N., Schmidt-Chanasit, J., Zeller, H., Reusken, C. Yellow fever in the diagnostics laboratory. Emerg Microbes Infect. 2018; 7 (1): 129.

5. Gould, E. A., de Lamballerie, X., Zanotto, P. M., et al. "Origins, evolution, and vector/host coadaptations within the genus Flavivirus". Adv Virus Res. 2003; 59: 277-314

6. Bryant, J. E., Holmes, E. C., and Barrett, A. D. "Out of Africa: A Molecular Perspective on the Introduction of Yellow Fever Virus into the Americas". PLoS Pathog. 2007; 3 (5): e75. Haddow, E. "The natural history of Yellow fever in Africa". Proceedings of the Royal Society of Edinburgh B. 2012; 191-227.

8. Charles, F. "The mosquito hypothetically considered as an agent in the transmission of Yellow fever poison". New Orleans Med and Sur J. $1881 ; 601-616$.

9. Chaves-Carballo, E. "Carlos Finlay and yellow fever: triumph over adversity". Mil Med. 2005; 881-885.

10. Staples, J. E., and Monath, T. P. Yellow fever: 100 years of discovery. JAMA. 2008; 9: 60-962 Barrett, A. D., and Higgs, S. "Yellow fever: a disease that has yet to be conquered". Annu Rev Entomol. 2007; 52: 209-29.

12. Burke, D. S., and Monath, T. P. Flaviviruses. In: Knipe D. M., and Howley, P. M (eds). Fields Virology. Lippincott, Williams \& Wilkins; Philadelphia: 2001: 1025-1043.

13. Nina, K. S., Hewad, L., Ousmane, F., et al. Biological and Phylogenetic Characteristics of Yellow Fever Virus Lineages from West Africa. J Virol. 2013; 2895-2907

14. Fontenille, D., Diallo, M. Mondo, M. et al. "First evidence of natural vertical transmission of Yellow fever virus in Aedes aegypti, its epidemic vector". Trans Roy Soc Trop Med and Hyg. 1997; 533-535

15. Center for Disease Control and Prevention. National Centre for Emerging and Zoonotic Infectious Diseases (NCEZID), Division of Vector-Borne Diseases (DVBD), 2019

16. Fernandez-Garcia, M. D., Mazzon, M., Jacobs, M., et al. Pathogenesis of flavivirus infections: using and abusing the host cell. Cell Host Microbe. 2009; 318-328

17. Bressanelli, S., Stiasny, K., and Allison, S. L. Structure of a flavivirus envelope glycoprotein in its low $\mathrm{pH}$ induced membrane fusion conformation. EMBO J. 2004; 728-738

18. Chung, K.M., Liszewski, M. K., Nybakken, G. West Nile virus non-structural protein NS1 inhibits complement activation by binding the regulatory protein factor $\mathrm{H}$. Proc Natl Acad Sci USA. 2006; 103 (50): 1911-1916.

19. Issur, M., Geiss, B. J., and Bougie, I. The flavivirus NS5 protein is a true RNA guanylyltransferase that catalyzes a two-step reaction to form the RNA cap structure. RNA. 2009; 15 (12): 2340-2350.

20. Miller, S., and Krijnse-Locker, J. Modification of intracellular membrane structures for virus replication. Nat Rev Microbiol. 2008; 6 (5): 363-374

21. Mackenzie, J. M., Jones, M. K., and Westaway, E. G. Markers for trans-Golgi membranes and the intermediate compartment localize to induced membranes with distinct replication functions in flavivirus-infected cells. J Virol. 1999; 73: 9555-9567

22. Roosendaal, J., Westaway, E. G., and Khromykh, A. Regulated cleavages at the West Nile virus NS4A-2K-NS4B junctions play a major role in rearranging cytoplasmic membranes and
Golgi trafficking of the NS4A protein. J Virol. 2006; 80 (9):4623-4632.

23. Welsch, S., Miller, S., Romero-Brey, I., et al. Composition and three-dimensional architecture of the dengue virus replication and assembly sites. Cell Host Microbe. 2009; 5 (4): 365-375.

24. Mackenzie, J. M., Kenney, M. T., and Westaway, E. G. West Nile virus strain Kunjin NS5 polymerase is a phosphoprotein localized at the cytoplasmic site of viral RNA synthesis. J Gen Virol. 2007; 88: 1163-1168.

25. Lorenz, I. C., Kartenbeck, J., Mezzacasa, A., et al. Intracellular assembly and secretion of recombinant subviral particles from tick-borne encephalitis virus. J Virol. 2003; 77 (7): 43704382 .

26. Li, L., Lok, S. M., Yu, I. M., et al. The flavivirus precursor membrane-envelope protein complex: structure and maturation. Science. 2008; 319 (5871): 1830-1844.

27. Paules, C. I., and Fauci, A. S. Yellow fever Once again on the radar screen in the Americas. N Engl J Med. 2017; 376 (15): 1397-1399.

28. World Health Organization. Yellow fever. http://www.who.int/csr/disease/yellowfev/en/ 2018.

29. Barrett, A. D. T. The re-emergence of Yellow fever. Science. 2018; 361:847-848

30. Faria, N. R., Kraemer, M. U. G., Hill, S. C., et al. Genomic and epidemiological monitoring of Yellow fever virus transmission potential. Science. 2018; 361: 894-899

31. Monath, T. P. Yellow fever: an update. Lancet Infect Dis. 2001; 1: 11-20

32. Domingo, C., Charrel, R. N., Schmidt-Chanasit, J., et al. Yellow fever in the diagnostics laboratory. Emerg Microbes Infect. 2018; 7 (1): 129.

33. Figueiredo, P. O., Silva, A. T. S., Oliveira, J. S., et al. Detection and molecular characterization of Yellow fever virus, 2017, Brazil. EcoHealth. 2018; 15 (4): 864-870.

34. Possas, C., Lourenço-de-Oliveira, R., Tauil, P. L. et al. Yellow fever outbreak in Brazil: the puzzle of rapid viral spread and challenges for immunization. Mem Inst Oswaldo Cruz. 2018; 10: e180278.

35. Freire, F. D., Gomes, C. H. M., Cardoso, P. S., et al. Yellow fever: An old disease, but with new challenges. Conexão Ci. 2018; 13: 79-86.

36. De Freitas, C. S., Higa, L. M., Sacramento, C. Q., et al. Yellow fever virus is susceptible to sofosbuvir both in vitro and in vivo. PLoS Negl Trop Dis. 2019; 13 (1): e0007072.

37. Tolle, M. A."Mosquito-borne diseases". Curr Probl Pediatr Adolesc Health Care. 2009; 39: 97-140

38. Woodall, J. P., and Yuill, T. M. "Why is the Yellow fever outbreak in Angola a 'threat to the entire world'?". Int J Infect Dis. 2016; 48: 9697.

39. World Health Organization. Eliminate Yellow fever Epidemics (EYE): a global strategy, 20172026. Wkly Epidemiol Rec. 2017; 92 (16): 193204.

40. World Health Organizations. Vaccines and vaccination against Yellow fever. WHO position paper. Wkly Epidemiol Rec. 2013; 88: 269-284

41. World Health Organization. Disease outbreak news: Yellow fever - Brazil 2017. http://www. who.int/csr/don/13-january-2017yellow-fever-brazil/en/.

42. Pan American Health Organization / World Health Organization. Epidemiological Update: Yellow Fever. 25 January 2019, Washington, D.C.: PAHO/WHO, 2019.

43. Chippaux, J.P., and Chippaux, A. Yellow fever in Africa and the Americas: a historical and epidemiological perspective. J Venom Anim Toxins Incl Trop Dis. 2018; 24:20.

44. World Health Organization. Yellow fever Fact sheet. 2016a. 
http://www.who.int/mediacentre/factsheets/fs1 00/en/. Accessed 21 Apr 2017

45. Jentes, E. S., Poumerol, G., and Gershman, M. D. The revised global yellow fever risk map and recommendations for vaccination, 2010: consensus of the Informal WHO Working Group on Geographic Risk for Yellow Fever. Lancet Infect Dis. 2011; 11: 622-632.

46. World Health Organization. The yellow fever outbreak in Angola and Democratic Republic of the Congo ends 2017.

http://www.afro.who.int/en/mediacentre/pressreleases/item/9377-the-yellowfever-outbreak-in-angola-and-democraticrepublic-of-the-congo-ends.html. Accessed 24 Apr 2017

47. World Health Organization. Yellow fever situation report - Angola 2016 http://www.who.int/emergencies/yellowfever/situation-reports/29-july-2016/en/. Accessed 21 Apr 2017

48. MacNamara, F. N. World Health Organization Bulletin. 1954; 11: 391401

49. Carey, D. E., Kemp, G. E., Troup, J. M., et al. Epidemiological aspects of the 1969 Yellow fever epidemic in Nigeria. Bull World Health Organ. $1972 ; 46$ (5): 645-651.

50. World Health Organization. Emergencies preparedness response. Yellow fever - Nigeria, 2019. Disease outbreak news.

51. Nigeria Centre for Disease Control. Yellow Fever Monthly Situation Report in Nigeria. May, 2019 Report. www.ncdc.gov.ng

52. Nigeria Centre for Disease Control. The NCDC is Aware of a Suspected Outbreak of Yellow Fever in Ebonyi State. 2019. www.ncdc.gov.ng 